\title{
RIGID ESOPHAGOSCOPY; \\ A TEACHING INSTITUTION EXPERIENCE
}

1. Assistant Professor ENT RMC Rawalpindi.

2. Assistant Professor ENT RMC Rawalpindi.

3. Assistant Professor Cardiology MBBS Medical College, Mirpur

4. Assistant Professor ENT MBBS Medical College, Mirpur

Correspondence Address: Dr. Mahboob Yazdani Khan Assistant Professor

ENT RM C Rawalpindi.

medicaldoctoronline@gmail.com

Article received on:

03/01/2017

Accepted for publication:

$15 / 04 / 2017$

Received after proof reading: 06/05/2017

\begin{abstract}
Dr. Mahboob Yazdani Khan', Dr. Ahmed Hasan Ashfaq ${ }^{2}$, Dr. Saeed Ahmed ${ }^{3}$, Dr. Faisal Bashir ${ }^{4}$
ABSTRACT... Objectives: To evaluate the various aspects of rigid esophagoscopy done in the ENT unit of Benazir Bhutto Hospital. Study Design: It was an observational study. Place and duration: ENT and Head and neck surgery unit Benazir Bhutto Hospital (EX-Rawalpindi General Hospital) Rawalpindi from Oct 2011 to Oct 2012. Patients and Methodology: This prospective study included all the rigid endoscopies done in a year time. Results: A total of 70 patients were included. Male to female ratio was 56:57. The age range was from 2 years to 85 years. 40 patients $(54.29 \%)$ of the total underwent esophagoscopy due to foreign body ingestion. 21 patients were children and 17 adults $(70 \%)$. All the 21 children (100\%) underwent rigid esophagoscopy because of foreign body ingestion. Conclusion: Foreign body esophagus is the most common indication of rigid esophagoscopy.
\end{abstract}

Key words: Rigid esopahgoscopy.

Article Citation: Khan MY, Ashfaq AH, Ahmed S, Bashir F. Rigid esophagoscopy; a teaching institution experience. Professional Med J 2017;24(5):713-716. DOI: $10.17957 / T P M J / 17.3864$

\section{INTRODUCTION}

Rigid Esophagoscopy is old and time-tested procedure. Rigid Esophagoscopy has been an integral part of the practice of otolaryngology for over a century. ${ }^{1}$ Use of rigid endoscope is reliable in removing FBs in the esophagus ${ }^{2}$ but at times associated with complications like perforation of Esophagus but fortunately Esophageal perforation following $\mathrm{FBI}$ is rare. ${ }^{3}$ Flexible Esophagoscopy has replaced rigid Esophagoscopy remarkably because of ease and less complication associated with it But Flexible Esophagoscopy has its own limits in terms of removal of foreign bodies, its availability in various setups and training of personnel. So at many centers rigid Esophagoscopy is the only facility both for diagnostic and therapeutic purposes. Moreover in in expert hands it is safe and highly valuable procedure especially in extraction of various types of foreign bodies in esophagus which is not possible with Fibreoptic Esophagoscopy. Rigid endoscopic extraction of foreign bodies under general anesthesia was found quite safe and effective procedure in dealing with all sort of foreign bodies. ${ }^{4}$

\section{MATERIAL AND METHODS}

This study was conducted at ENT Department Benazir Bhutto Hospital, Rawalpindi. Data of all the patients admitted for Esophagoscopy was collected routinely whenever a case was done. Many of the procedures were done by the present author working as Assistant Professor/visiting surgeon at this institute All the required routine investigations were done in all cases including $X$-rays soft tissue neck lateral and AP views chest $\mathrm{X}$-rays and as per case Barium swallow and CT scans as well. All the records were kept routinely as per case for one year. On conclusion of a year all the data was analyzed in the terms of age, gender and purpose of Endoscopy. The results were analyzed on those parameters and various purposes of Endoscopy were determined in various age groups. The cases of foreign body ingestion were further analyzed on the basis of age, gender and type of foreign body ingested.

\section{RESULTS}

There were total 70 patients who underwent rigid Esophaygoscopy for various purposes at Benazir Bhutto Hospital, Rawalpindi from Oct 2011Oct 2012. The females outnumbered males as 
there were $44(57.67 \%)$ females with compared to males $26(42.33 \%)$. The age range was from 2 years -85 years. Among them $20(28.58 \%)$ were children and 50 (71.42\%) adults. Among children male/female were equal 10 each in both genders. Among 50 adults $36(72 \%)$ were females and $14(28 \%)$ were males.

The most common indication of Esophagoscopy was foreign body esophagus in 40 patients $(62.8 \%)$ out of 70 . The incidence of foreign body esophagus among children and adults was same with 20 patients in each group. Among children male to female ratio was equivalent with 10 patients in each group. Among adults malefemale ratio was also equivalent with 10 patients in each group. As for the nature of foreign body children had coin in all the 20 patients (100\%) on the other hand in adults $14(70 \%)$ had bone as foreign body esophagus and $5(25 \%)$ had meat bolus and 1 (5\%) had surgical gauze as foreign body. Among the 5 patients having meat bolus as foreign body 4 were above 40 years of age with the age range from 43-52 years. All the patients with meat bolus as foreign body esophagus were females and none was a male. Among 14 patients with bone as foreign body 9 were males and 5 were females. All were adults with age group from 17-40 years.

The most common foreign body in pediatric age group was coin among all 20 (100\%) patients. Among adults bone was the most common foreign body 14 (70\%) of all the cases, 5 (20\%) meat bolus and 1 (5\%) unusual foreign body, piece of gauze was found. The next most common indication of esophagoscopy was dysphagia among 13 patients (18.58\%). Among them 4 were males (30.77\%) and rest were females (69.23\%). The age range among males was 10-85 years. Among females the age group ranged from 3558 years none was from pediatric age group. The Next most common indication of esophagoscopy was pharyngeal web in 8 patients $(11.43 \%)$. All the patients were females $(100 \%)$ with no males $(0 \%)$. The age ranged from $21-44$ years. The rest of the patients who underwent esophagoscopy included ca esophagus in 2 patients (2.85\%) both were females (100\%) with age range 47-68 years while 1 patient was of zenker's diverticulum and postcricoid carcinoma with age range 40-55 years.

\section{DISCUSSION}

The importance of subject of rigid esophagoscopy is stressed by the fact that this modality has diagnostic and therapeutic importance. The recent development of fiber optic endoscopy has revolutionized the field of endoscopy but till date the rigid endoscopy has its dominance in various aspects of endoscopy.

The rigid endoscopy is associated with dreadful complication like perforation of esophagus, mediastinitis, pneumonitis and trauma to teeth gums, pharynx and larynx but as shown in this study no complications were encountered. This was because of proper patient diagnosis, preparation and endoscopies done by the senior faculty or under their direct supervision so rigid endoscopy can be as safe as fiber optic endoscopy which is also not without hazards even being done under local anesthesia. Rigid esophagoscopy is used for children and adults because of its large working channel. Rigid instruments are considered reliable and safe for extracting foreign bodies.

In this study it has been observed that foreign body esophagus is the most common indication for rigid endoscopy as $51.95 \%$ of the cases undergoing rigid esophagoscopy were due to ingestion of foreign body. Hariga et $\mathrm{al}^{8}$ showed that most common indication for rigid endoscopy was foreign body in $87.7 \%$ of their patients in contrast to our study where foreign body was the major indication but our percentage was low $62.85 \%$. This may be due to a chance occurrence or due to more awareness in our part of the world. In our study the most common foreign body was coin (100\%) among the children in accordance to other studies. ${ }^{9,10,11}$ which was due to less awareness and carelessness on the part of parents and elders to hand over or let play children with the metallic coins who are prone to ingest everything handed over to them.

In our series bone was the second most common 
foreign body after coin. In our series males were more common than the females in ingestion of bones and were in age group 17-40. This may have been due to eating habits of males in groups and outside restaurants where things are taken in a light and competitive mood which leads to accidental ingestion of various sizes of bones. In this study meat bolus ingestion was the 3rd most common foreign body as $20 \%$ of the foreign body cases. The most important finding in this group was that all (100\%) were females and were adults with age range 43-53. This finding may need to be further investigated as Plummer Vinson syndrome is most common in females especially in this age group with higher risk of malignant strictures in females above 40 years.

The next most common indication after foreign body esophagus was the dysphagia in $13(18.58 \%)$ patients. In contrast to this another study ${ }^{3}$ showed in their series that dysphagia was the most common indication $57.5 \%$. This may be due to prevalence of different causes of dysphagia in their area and a high incidence of carcinoma Esophagus. The 3rd most common indication in this series was web formation in $8(11.3 \%)$ patients and all of them (100\%) were females in age range of 21-44. Most common cause of web is Plummer- Vinson's syndrome and its very common in females Endoscopic dilatation is the procedure of choice in the treatment of cervical web of the esophagus. ${ }^{12}$ Patients are managed with dilation using through-the-scope controlled radial expansion balloon followed by oral iron and folic acid supplementation. ${ }^{13}$ Plummer Vinson Syndrome is precursor of Post cricoid Carcinoma mostly in female so early detection is important to prevent this complication. The next indications in this series were carcinoma esophagus carcinoma post cricoid region and zenker,s diverticulum, $2.85 \% / 1.43 \%$ and $1.43 \%$ respectively. Endoscopic biopsy to confirm the esophageal malignancy is an effective way of diagnosis. ${ }^{14}$

Rigid esophagoscopy is also effective in dilatation of esophageal strictures other than Plummer Vinson syndrome but in our series, there was only one case which underwent esophageal dilatation with good results. Endoscopic dilatation is modestly effective in achieving adequate dilatation and revealing dysphagia. ${ }^{15}$ Although there was no complication of rigid esophagoscopy in our series and no morbidity and mortality but esophageal rupture can be diagnosed by rigid endoscopy ${ }^{16}$ more over morbidity and mortality rates are inacceptable range in rigid esophagoscopy 4.5 $\%$ and 1.5 percent respectively. ${ }^{7}$

\begin{tabular}{|c|c|c|}
\hline Gender & Male & Female \\
\hline Percentage & $57.67 \%$ & $42.33 \%$ \\
\hline
\end{tabular}

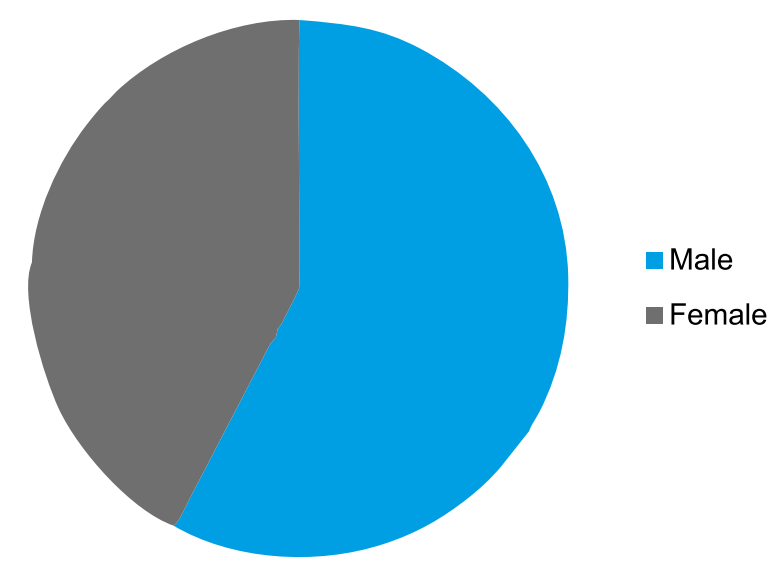

Male and Female ratio

\section{CONCLUSION}

Rigid endoscopy is still the best tool to treat the foreign bodies' esophagus and other indications in expert hands.

\section{Copyright(c) 15 Apr, 2017.}

\section{REFERENCES}

1. Gustafson LM, Tami TA. Flexible versus rigid esophagoscopy: a practical comparison for otolaryngologists. CurrOpinOtolaryngol Head Neck Surg. 2000; 8(3):227-31.

2. Umihanić Š, Brkić F, Umihanić Š, Hodźić S. Foreign body impaction in esophagus: experiences at Ear-Nose-Throat Clinic in Tuzla, 2003-2013. Kulak BurunBoğazlhtisDerg KBB J Ear Nose Throat. 2015; 25(4):214-8.

3. Peters NJ, Mahajan JK, Bawa M, Chabbra A, Garg R, Rao KLN. Esophageal perforations due to foreign body impaction in children. $J$ Pediatr Surg. 2015; 50(8):1260-3. 
4. Ajmal M, Mahmood T. Esophageal foreign bodies. A clinical study of 240 patients. Prof Med J. 1996 Dec; 3(4):283-7.

5. Nadir A, Sahin E, Nadir I, Karadayi S, Kaptanoglu M. Esophageal foreign bodies: 177 cases. Dis Esophagus. 2011 Jan 1; 24(1):6-9.

6. Weissberg D, Refaely $Y$. Foreign bodies in the esophagus. Ann Thorac Surg. 2007 Dec; 84(6):1854-7.

7. Nadeem A, Bilal A, Afridi K, others. A three-year audit of rigid oesophagoscopy at Lady Reading Hospital Peshawar. J Ayub Med Coll Abbottabad JAMC. 2005; 18(1):11-3.

8. Hariga I, Khamassi K, Zribi S, Amor MB, Gamra OB, Mbarek $C$, et al. Management of foreign bodies in the aerodigestive tract. Indian $\mathrm{J}$ Otolaryngol Head Neck Surg off Publ Assoc Otolaryngol India. 2014 Jan; 66(Suppl 1):220-4.

9. Muñoz FM, Maluje JR, Saitua DF. [Gastrointestinal foreign body in children]. Rev ChilPediatr. 2014; 85(6):682-9.

10. Khan MA, Hameed A, Choudhry AJ. Management of foreign bodies in the esophagus. J Coll Physicians
Surg JCPSP. 2004; 14(4):218-20.

11. Rodríguez $H$, Cuestas $G$, Botto $H$, Nieto $M$, Cocciaglia A, Gregori D. [Foreign bodies in esophagus in children: case series]. Arch Argent Pediatría. 2013 Jun; 111(3):e62-5.

12. Hefaiedh R, Boutreaa Y, Ouakaa-Kchaou A, Gargouri D, Elloumi $\mathrm{H}$, Kochlef $\mathrm{A}$, et al. Plummer-Vinson syndrome. Tunis Médicale. 2010 Oct; 88(10):721-4.

13. Goel A, Lakshmi CP, Bakshi SS, Soni N, Koshy S. Single-center prospective study of Plummer-Vinson syndrome. Dis Esophagus off J IntSoc Dis Esophagus ISDE. 2015 Jul 30;

14. Bukhari U, Siyal R, Memon FA, Memon JH, others. Oesophageal carcinoma: a review of endoscopic biopsies. Pak J Med Sci. 2009; 25(5):845-8.

15. Rehman S, Hameed K, Khan IM. Endoscopic dilatation for caustic esophageal strictures. J Postgrad Med Inst Peshawar-Pak [Internet]. 2011 [cited 2015 Aug 2]; 21(4). Available from: http://jpmi.org.pk/index.php/jpmi/ article/viewFile/186/98.

16. Fatimi $\mathrm{SH}$, Sheikh $\mathrm{S}$, Ali AA. Primary repair of an esophageal rupture using pleural flap. J Coll Physicians Surg JCPSP. 2006; 16(4):309-10.

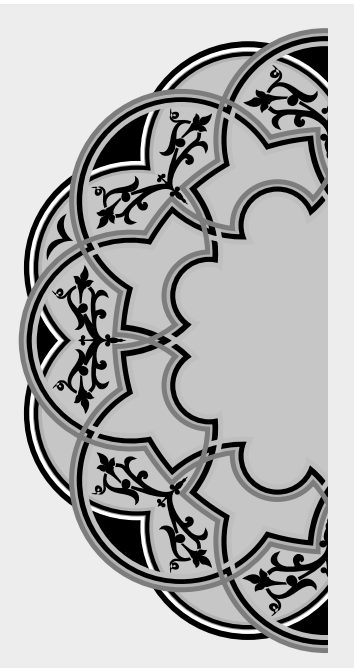

\title{
"Blood makes you related, Loyalty makes you family."
}

\author{
Unknown
}

\section{AUTHORSHIP AND CONTRIBUTION DECLARATION}

\begin{tabular}{c|l|l|l|} 
Sr. \# & \multicolumn{1}{|c|}{ Author-s Full Name } & \multicolumn{1}{|c|}{ Contribution to the paper } & Author=s Signature \\
\hline 1 & Dr. Mahboob Yazdani Khan & Principal Author \\
\hline 2 & Dr. Ahmed Hasan Ashfaq & Co-author \\
3 & Dr. Saeed Ahmed & Co-author \\
4 & Dr. Faisal Bashir & Co-author & \\
\hline
\end{tabular}

